\title{
1 Micro-scale variability enhances trophic transfer and potentially \\ 2 sustains biodiversity in plankton ecosystems
}

4 Anupam Priyadarshi ${ }^{\mathrm{a}}$, Sandip Mandal ${ }^{\mathrm{a}, \mathrm{b}}, \mathrm{S}$. Lan $\mathrm{Smith}^{\mathrm{c}}$, Hidekatsu Yamazaki ${ }^{\mathrm{*}}{ }^{*}$

5 aDepartment of Ocean Sciences, Tokyo University of Marine Science and Technology,

6 Minato-ku, Tokyo 108-8477 Japan

7 bPublic Health Foundation of India, Delhi NCR 44, Gurgaon 122002 India

$8{ }^{\mathrm{c}}$ Marine Ecosystem Dynamics Research Group, Research and Development Centre for

9 Global Change, Japan Agency for Marine-Earth Science and Technology, 3173-25 Showa-

10 machi, Kanazawa-ku, Yokohama 236-0001 Japan

$11 *$ Corresponding author

12 Email address: AP: anupam240@gmail.com, SM: sandipccmb@gmail.com,

SLS: 1animal@jamstec.go.jp, HY: hide@,kaiyodai.ac.jp 


\section{Abstract:}

26 We develop moment closure approximations to represent micro-scale spatial 27 variability in the concentrations of nutrients $(N)$, phytoplankton $(P)$ and zooplankton $(Z)$ in 28 an NPZ model, which we apply to examine the impact of different levels of micro-scale

29 variability on both ecosystem dynamics and trophic transfer. Accounting explicitly for both 30 the mean-field and fluctuating components of each prognostic variable in the NPZ model 31 yields different dynamics for the mean-field concentrations, as well as lower phytoplankton 32 biomass and greater zooplankton biomass, compared to the conventional NPZ model 33 without micro-scale variability. The biomass of zooplankton consistently increases with 34 increasing total micro-scale variability, and a minimum threshold of such variability is 35 required for the existence of stable steady state solutions in the NPZ closure model. 36 Compared to the conventional NPZ model, the domain of parameter space over which stable 37 solutions exist is larger than for the NPZ closure model, and this stable domain widens with 38 increasing total variability. The latter result suggests that natural systems with greater 39 micro-scale variability may have the potential to sustain greater biodiversity. We find that 40 with the NPZ closure model: 1) the stability domains increases with micro-scale variability, 41 2) increase of the level of total micro-scale variability enhances trophic transfer, i.e. 42 increases the biomass of zooplankton, and 3) the coefficient of variation $\left(C V_{P}\right)$ of 43 phytoplankton increases with micro-scale variability.

45 Keywords: spatial heterogeneity, intermittency, food chain, coefficient of variation 46 


\section{Introduction:}

Plankton constitute the productive base of aquatic ecosystems and play vital roles in

49 the global cycles of nutrients and carbon. The complex interactions of plankton, other

50 organisms and biogenic particles in turbulent flows drive plankton dynamics and nutrient

51 cycling with influences expected to be accumulative across multiple scales (Franks et al.,

52 1986, 2002; Loreau 2001; Azam et al., 2004). Theoretical explanations are established by

53 means of various models (from simple two-component systems to highly complex multi-

54 component systems) using a set of differential equations (Steel et al., 1981, 1992; Fasham

55 1993; Edward et al., 1996; Huisman et al., 2006). Nearly all such models have been

56 developed based on the mean-field assumption, in which each concentration is treated as

57 uniform (i.e., well mixed) below the spatial resolution of the model, e.g. within a modeled

58 batch incubator, or within each grid cell of a 1-D or 3-D numerical model. However, Dobell

59 et al., $(2009,2014)$ reported that high micro-scale variance of phytoplankton at mm scale is

60 observed ubiquitously and it plays a major role in determining plankton population

61 dynamics.

62 Although equations for plankton growth rates are typically based on controlled

63 laboratory experiments, in reality plankton population dynamics differ from such idealized

64 laboratory settings, which cannot account for relevant biological and physical factors

65 (Berntnall et al., 2003; Wallhead et al., 2008). For example, spatial heterogeneity in

66 plankton distribution is well known among empirical ecologists due to large-scale turbulent

67 mixing (Okubo and Levin 1980). Berntnall et al., (2003) have shown that using second

68 order moment approximations to account for spatial heterogeneity yields results very

69 different from the typical first order moment (i.e., mean field) approximation. Furthermore,

70 Wallhead et al., (2008) find that at scales larger than $10 \mathrm{~m}$ heterogeneously distributed

71 plankton population respond differently compared to well-mixed conditions. 
72 To account for the effects of dynamical nonlinearity acting on spatial variability, 73 which may lead to failure of the mean field approximation, moment closure methods have 74 been applied in terrestrial ecology (Bolker et al., 1997; Lewis et al., 2000; Murrell et al., 75 2004; Barraquand et al., 2013) and terrestrial epidemiology (Ferguson et al., 2001; Filipe et 76 al., 2001, 2003). In spatial predator-prey models (Murdoch and Oaten, 1975; Weisser et al., 77 1997; Neubert et al., 2002; Murdoch et al., 1992) dispersal can promote stability (Jansen, 78 1995). Several spatial models found that spatial or temporal heterogeneity can lead to a 79 stable equilibrium at the local and hence also global scale (Crowley, 1981; Holt and Hassell, 80 1993; McCann et al., 2000). On the other hand, dispersal enhances the persistence of 81 unstable host-parasitoid dynamics in host-parasitoid spatial models (Briggs \& Hoopes 82 2004), and other studies (Allen 1975; Reeve 1988; Rohani et al., 1996) found destabilizing 83 effects of spatial dispersal. These previous studies all considered spatial heterogeneity at 84 scales above $10 \mathrm{~m}$.

85 The moment closure model introduced in Mandal et al., (2014) differs from previous 86 closure approaches in several respects. It is based on observed fluctuations in the 87 distribution of micro-scale phytoplankton data (Doubell et al., 2009, 2014). Also, it uses a 88 spatially explicit second order moment approximation to calculate the dynamics of the 89 variance and covariance of each variable. The mean fields are averaged qualities at the $\mathrm{m}$ 90 scale, and the fluctuating fields are qualified at the $\mathrm{mm}$ scale. Due to explicit equations for 91 the rate of change of means, variances and covariances, the second order moments impact 92 the dynamics of the mean field and vice-versa.

93 Mandal et al., (2014) purposely kept their plankton ecosystem model simple by 94 considering only phytoplankton and nutrient. However, zooplankton grazing strongly affects 95 the biomass and composition of phytoplankton communities (Storm et al., 1991; Carpenter 96 et al., 1984; Sterner 1989). Although nutrient inputs determine the potential biomass of 
97 phytoplankton, zooplankton grazing can cause a significant deviation from simple nutrient-

98 phytoplankton dynamics (Carpenter et al., 1988; Yool 1998). Consequently, nutrient-

99 phytoplankton-zooplankton (NPZ) models have become standard tools for studying

100 plankton ecosystems in the ocean. Here we extend the closure modelling approach to an

101 NPZ closure model, and for the first time consider the effects of micro-scale variability on

102 trophic transfer and dynamics of planktonic ecosystems with multiple trophic levels. We

103 define the "micro-scale variability", $\beta$, in a similar manner as in Mandal et al., (2014), as the

104 sum of all variances and covariances of fluctuating components divided by the square of the

105 sum all mean-field concentrations. This study focuses on how micro-scale variability, $\beta$,

106 impacts the modelled ecosystem, and specifically addresses the following questions:

107 (a) How does micro-scale variability impact ecosystem stability?

108 (b) How does micro-scale variability affect ecosystem dynamics and trophic transfer?

109 (c) How is the coefficient of variation of phytoplankton $\left(C V_{P}\right)$, which is an observable

110 quantity, related to micro-scale variability?

111 The manuscript has been arranged as follows: the detailed model formulations of the

112 conventional NPZ and the NPZ closure models are described in the section 2, "Model

113 Formulation". The parameter choice and the discussion of model simulations are described

114 in the Section 3, "Results and discussion". The interpretation of the results is also discussed

115 throughout the section "Results and Discussion", and the questions posed in the introduction

116 are answered in the Section 4, "Conclusions".

\section{2. Model Formulation:}

$119 \quad 2.1$ Conventional NPZ model

120 Many studies have used controlled laboratory settings to determine species-specific 121 grazing rates (Peter et al., 1984; Bertilsson et al., 2003) and other studies have estimated 
122 grazing rates for zooplankton communities on phytoplankton communities (Sprules, 1980;

123 Cyr et al., 1998). However, zooplankton-grazing functional forms remain a major

124 uncertainty in ecological modeling. Several explicit grazing functional forms (linear,

125 Holling type II, Ivelev, sigmoidal, etc.) have been proposed and studied (Franks et al., 1986,

126 2002; Fasham 1993, Edward et al., 1996). For this first study to develop an NPZ closure

127 model, we assumed a linear grazing rate, because it is the simplest among many options.

128 Taking $N, P$ and $Z$ as the biomass of nutrient, phytoplankton and zooplankton in the 129 plankton ecosystem, a simple conventional NPZ model (based on Franks et al., 1986, 2002)

130 can be explicitly described by the following set of differential equations:

$$
\frac{d P}{d t}=v_{\max } \frac{N}{K+N} P-M P-R P Z
$$

$$
\frac{d Z}{d t}=(1-\gamma) R P Z-G Z
$$

134 In the above (1a-c), the phytoplankton response to light is considered as a constant $\left(v_{\max }\right)$

135 and the growth phytoplankton is considered to follow a Monod expression $\frac{N}{K+N}$, where $K$ 136 denotes the half-saturation constant (MacIsaac et al., 1969; Eppely et al., 1969; Lehman et 137 al., 1975). At this stage, the model is 0 -dimensional, so $v_{\max }$ does not depend on the 138 intensity of light. The specific mortality rates of phytoplankton, $M$, and zooplankton, $G$, are 139 assumed constant, and the zooplankton assimilation $(1-\gamma)$ is a simple linear function of 140 food ingested., A linear zooplankton grazing function, $R P$, is considered, in which $R$ is the 141 specific grazing rate of zooplankton. The total nutrient within the NPZ model (1a-c) is 142 conserved so that, 
144 where $A$ represents total nutrient content in the system.

\subsection{NPZ Closure Model}

To derive the NPZ closure model from the conventional NPZ model (1a-c), each of

148 its components is considered to be a function of both time $(t)$ and space $(s)$ :

$149 \quad N(s, t)=N_{0}(s, t)+N^{\prime}(s, t), P(s, t)=P_{0}(s, t)+P^{\prime}(s, t), Z(s, t)=Z_{0}(s, t)+Z^{\prime}(s, t)$

150 where $N_{0}, P_{0}$ and $Z_{0}$ are spatial mean values of nutrient, phytoplankton and zooplankton

151 respectively, and $N^{\prime}, P^{\prime}$ and $Z^{\prime}$ are their fluctuating components with respect to

152 corresponding mean values. According to Foloni-Neto et al., (2015), horizontal and vertical

153 sampling for micro-scale phytoplankton distribution reveal the same statistics at the $\mathrm{cm}$

154 scale. The statistics are also similar at the $\mathrm{mm}$ scale except for the extreme values.

155 Therefore, we consider the statistics of the fluctuating components to be isotropic, i.e.

156 independent of the direction of sampling. At any particular time, the spatial average of each

157 fluctuating component is zero $\left(\left\langle N^{\prime}(s)\right\rangle=\left\langle P^{\prime}(s)\right\rangle=\left\langle Z^{\prime}(s)\right\rangle=0\right)$, while its temporal average

158 can be nonzero, which also implies that spatial average of each variable equals its mean

159 value $\langle N(s)\rangle=N_{0}(s),\langle P(s)\rangle=P_{0}(s) \operatorname{and}\langle Z(s)\rangle=Z_{0}(s)$. Putting (3) in equation (1a-c) and

160 retaining only up to second-order terms in Taylor expansion, yields the following set of

161 equations for the temporal variation of mean, variance and covariance of $N, P$ and $Z$ :

$162 \frac{d P_{0}}{d t}=v_{\max }\left(\frac{N_{0}}{K+N_{0}} P_{0}-\frac{K P_{0}}{\left(K+N_{0}\right)^{3}}\left\langle N^{\prime 2}\right\rangle+\frac{K}{\left(K+N_{0}\right)^{2}}\left\langle N^{\prime} P^{\prime}\right\rangle\right)$

$$
-M P_{0}-R\left(P_{0} Z_{0}+\left\langle P^{\prime} Z^{\prime}\right\rangle\right)
$$

$163 \frac{d Z_{0}}{d t}=(1-\gamma) R\left(P_{0} Z_{0}+\left\langle P^{\prime} Z^{\prime}\right\rangle\right)-G Z_{0}$ 
$164 \frac{d N_{0}}{d t}=-v_{\max }\left(\frac{N_{0}}{K+N_{0}} P_{0}-\frac{K P_{0}}{\left(K+N_{0}\right)^{3}}\left\langle N^{\prime 2}\right\rangle+\frac{K}{\left(K+N_{0}\right)^{2}}\left\langle N^{\prime} P^{\prime}\right\rangle\right)$

$$
+M P_{0}+\gamma R\left(P_{0} Z_{0}+\left\langle P^{\prime} Z^{\prime}\right\rangle\right)+G Z_{0}
$$

$$
\begin{gathered}
\left.\frac{d\left\langle N^{\prime 2}\right\rangle}{d t}=-2 v_{\max }\left(\frac{N_{0}}{K+N_{0}}\left\langle N^{\prime} P^{\prime}\right\rangle+\frac{K P_{0}}{\left(K+N_{0}\right)^{2}}<N^{\prime 2}\right\rangle\right)+2 M\left\langle N^{\prime} P^{\prime}\right\rangle \\
+2 \gamma R\left(Z_{0}\left\langle N^{\prime} P^{\prime}\right\rangle+P_{0}\left\langle N^{\prime} Z^{\prime}\right\rangle\right)+2 G\left\langle N^{\prime} Z^{\prime}\right\rangle
\end{gathered}
$$

166

$$
\begin{gathered}
\frac{d\left\langle P^{\prime 2}\right\rangle}{d t}=2 v_{\max }\left(\frac{N_{0}}{K+N_{0}}\left\langle P^{\prime 2}\right\rangle+\frac{K P_{0}}{\left(K+N_{0}\right)^{2}}\left\langle N^{\prime} P^{\prime}\right\rangle\right)-2 M\left\langle P^{\prime 2}\right\rangle \\
-2 R\left(Z_{0}\left\langle P^{\prime 2}\right\rangle+P_{0}\left\langle P^{\prime} Z^{\prime}\right\rangle\right)
\end{gathered}
$$

$$
\begin{aligned}
& \frac{d\left\langle Z^{\prime 2}\right\rangle}{d t}=2(1-\gamma) R\left(Z_{0}\left\langle P^{\prime} Z^{\prime}\right\rangle+P_{0}\left\langle Z^{\prime 2}\right\rangle\right)-2 G\left\langle Z^{\prime 2}\right\rangle \\
& \begin{aligned}
\frac{d\left\langle N^{\prime} P^{\prime}\right\rangle}{d t}=v_{\max }\left(\frac{N_{0}}{K+N_{0}}\left(\left\langle N^{\prime} P^{\prime}\right\rangle-\left\langle P^{\prime 2}\right\rangle\right)+\frac{K P_{0}}{\left(K+N_{0}\right)^{2}}\left(\left\langle N^{\prime 2}\right\rangle-\left\langle N^{\prime} P^{\prime}\right\rangle\right)\right) \\
-M\left(\left\langle N^{\prime} P^{\prime}\right\rangle-\left\langle P^{\prime 2}\right\rangle\right)+G\left\langle P^{\prime} Z^{\prime}\right\rangle \\
+R Z_{0}\left(\gamma\left\langle P^{\prime 2}\right\rangle-\left\langle N^{\prime} P^{\prime}\right\rangle\right)+R P_{0}\left(\gamma\left\langle P^{\prime} Z^{\prime}\right\rangle-\left\langle N^{\prime} Z^{\prime}\right\rangle\right)
\end{aligned}
\end{aligned}
$$

$$
\begin{aligned}
\frac{d\left\langle P^{\prime} Z^{\prime}\right\rangle}{d t}=v_{\max } & \left(\frac{N_{0}}{K+N_{0}}\left\langle P^{\prime} Z^{\prime}\right\rangle+\frac{K P_{0}}{\left(K+N_{0}\right)^{2}}\left\langle N^{\prime} Z^{\prime}\right\rangle\right)-(M+G)\left\langle P^{\prime} Z^{\prime}\right\rangle \\
+ & R Z_{0}\left((1-\gamma)\left\langle P^{\prime 2}\right\rangle-\left\langle P^{\prime} Z^{\prime}\right\rangle\right)+R P_{0}\left((1-\gamma)\left\langle P^{\prime} Z^{\prime}\right\rangle-\left\langle Z^{\prime 2}\right\rangle\right)
\end{aligned}
$$

$$
\begin{aligned}
\frac{d\left\langle N^{\prime} Z^{\prime}\right\rangle}{d t}=-\nu_{\max } & \left(\frac{N_{0}}{K+N_{0}}\left\langle P^{\prime} Z^{\prime}\right\rangle+\frac{K P_{0}}{\left(K+N_{0}\right)^{2}}\left\langle N^{\prime} Z^{\prime}\right\rangle\right)+M\left\langle P^{\prime} Z^{\prime}\right\rangle \\
+ & G\left(\left\langle Z^{\prime 2}\right\rangle-\left\langle N^{\prime} Z^{\prime}\right\rangle\right)+R Z_{0}\left((1-\gamma)\left\langle N^{\prime} P^{\prime}\right\rangle+\gamma\left\langle P^{\prime} Z^{\prime}\right\rangle\right) \\
+ & R P_{0}\left((1-\gamma)\left\langle N^{\prime} Z^{\prime}\right\rangle+\gamma\left\langle Z^{\prime 2}\right\rangle\right)
\end{aligned}
$$
while the next three (4d-f) represent the rates of change for their respective variance. The

174 last three equations (4g-i) describe the rates of change for the covariances. The following 175 conservation relationships hold among these nine equations:

$$
N_{0}+P_{0}+Z_{0}=\text { constant }=A
$$


(ii) The total spatial variability in the system is conserved:

$$
\left\langle P^{\prime 2}\right\rangle+\left\langle Z^{\prime 2}\right\rangle+\left\langle N^{\prime 2}\right\rangle+2\left(\left\langle N^{\prime} P^{\prime}\right\rangle+\left\langle P^{\prime} Z^{\prime}\right\rangle+\left\langle N^{\prime} Z^{\prime}\right\rangle\right)=\text { constant }=B
$$

We define a new dimensionless quantity called "micro-scale variability" $\beta$ as:

$$
\beta=\frac{B}{A^{2}}=\frac{\left\langle P^{\prime 2}\right\rangle+\left\langle Z^{\prime 2}\right\rangle+\left\langle N^{\prime 2}\right\rangle+2\left(\left\langle N^{\prime} P^{\prime}\right\rangle+\left\langle P^{\prime} Z^{\prime}\right\rangle+\left\langle N^{\prime} Z^{\prime}\right\rangle\right)}{\left(N_{0}+P_{0}+Z_{0}\right)^{2}}
$$

which represents a standardized measure of total variability in the closure model. Mandal et al., (2014), by non-dimensionalizing their NP model, showed that the model dynamics

184 depend critically on $\beta$. We have similarly non-dimensionalized our NPZ closure model to 185 derive a set of equations explicitly in terms of $\beta$ (Supplement S1.2.2).

In the NPZ closure model, mean of zooplankton $z_{0}$ (dimensionless), $Z$-variance $\left\langle z^{\prime 2}\right\rangle$

187 (dimensionless), and micro-scale variability, $\beta$, have the following relation (See Supplement 188 S1.2.2):

$189 \quad\left(z_{0}\right)^{2}=\beta\left\langle z^{\prime 2}\right\rangle$

190 Where, the $Z$-variance $\left\langle z^{\prime 2}\right\rangle$ is always non-negative for the biologically feasible solutions

191 and therefore, zooplankton mean $z_{0}$ always increases with micro-scale variability, $\beta$. This

192 implies that spatial variability should enhance trophic transfer in plankton food webs.

\section{3. Results and Discussion:}

\section{$194 \quad 3.1$ Parameter Range for Stability}

195 The numerical simulations are carried out with suitable choices of biologically 196 feasible parameter values (Table 1) based on empirical and theoretical studies (Sprules et 197 al., 1980; Peter et al., 1984; Franks et al., 1986; Storm et al., 1991) to investigate the global 198 behavior of conventional and closure models. We have also present extensive bifurcation 199 analyses (Supplement) to identify the parameter domain in which the stable steady state 200 solutions occur. 
201 Table 1. Parameter values and ranges for dimensional and dimensionless model

\begin{tabular}{|c|c|c|c|c|c|}
\hline $\begin{array}{l}\text { Para } \\
\text { Meter }\end{array}$ & Description & $\begin{array}{l}\text { Reported } \\
\text { value }\end{array}$ & $\begin{array}{l}\text { Dimen- } \\
\text { sionless } \\
\text { quantity }\end{array}$ & $\begin{array}{l}\text { Dimen- } \\
\text { Sionless } \\
\text { Values }\end{array}$ & $\begin{array}{l}\text { Inves- } \\
\text { gated } \\
\text { Range }\end{array}$ \\
\hline$A$ & $\begin{array}{l}\text { Sum of mean } \\
\text { nitrogen } \\
\text { contain }\end{array}$ & $\begin{array}{l}2 \mu \mathrm{g} \mathrm{N}^{-1} \\
\text { (Franks et al., } \\
1986 \text { ) }\end{array}$ & ------ & ------ & ------ \\
\hline$v_{\max }$ & $\begin{array}{l}P \text {-maximum } \\
\text { growth rate }\end{array}$ & $\begin{array}{l}2 \text { day }^{-1} \\
\text { (Franks et al., } \\
\text { 1986; Clark et } \\
\text { al., 2000) }\end{array}$ & ------ & ------ & $0.5-2$ \\
\hline K & $\begin{array}{l}\text { Half- } \\
\text { saturation } \\
\text { uptake } \\
\text { constant }\end{array}$ & $\begin{array}{l}0.6-1.8 \mu \mathrm{g} \mathrm{N} 1^{-} \\
\text {(Eppely et al., } \\
\text { 1969; Lehman } \\
\text { et al., 1975; } \\
\text { Edward 1996) }\end{array}$ & $k=K / \mathrm{A}$ & $0.3-0.9$ & $0-2.5$ \\
\hline$M$ & $\begin{array}{l}\text { P-mortality } \\
\text { rate }\end{array}$ & $\begin{array}{l}\text { 0.07-0.9 day }{ }^{-1} \\
\text { (Lehman et } \\
\text { al., 1975; Cyr } \\
\text { 1992, 1998; } \\
\text { Edward 1996) }\end{array}$ & $m=M / v_{\max }$ & $\begin{array}{l}0.035- \\
0.45\end{array}$ & $0-1$ \\
\hline$R$ & Z-grazing rate & $\begin{array}{l}0.4-1.4 \quad \text { day }^{-1} \\
\mathrm{~N}^{-1} \text { (Sprules et } \\
\text { al., 1980; Cyr } \\
\text { 1992, 1998; } \\
\text { Edward 1996; } \\
\begin{array}{l}\text { Bertilsson et } \\
\text { al., 2003) }\end{array}\end{array}$ & $r=R A / v_{\max }$ & $0.4-1.4$ & $0-2.5$ \\
\hline$G$ & $\begin{array}{l}\text { Z-mortality } \\
\text { rate }\end{array}$ & $\begin{array}{l}0.1-2.0 \quad \text { day }^{-1} \\
\text { (Cyr 1998; } \\
\text { Edward 1996; } \\
\begin{array}{l}\text { Bertilsson et } \\
\text { al., 2003) }\end{array}\end{array}$ & $g=G / v_{\max }$ & $0.05-1$ & $0-1$ \\
\hline$\gamma$ & $\begin{array}{l}\text { Unassimilated } \\
\text { grazing } \\
\text { fraction }\end{array}$ & $\begin{array}{l}0.3 \\
\text { (Sprules 1980; } \\
\text { Franks 2002) }\end{array}$ & $\gamma$ & 0.3 & 0.3 \\
\hline
\end{tabular}


203 The simulations of dimensionless conventional (S3-S4) and closure NPZ models (S20.1-

204 S20.7) (see the Supplement S2), are carried out with following parametric values:

$$
r=0.5, m=0.3, g=0.15, k=0.5, \gamma=0.3
$$

206 The above parameter set (9) satisfies the analytic conditions (S23) obtained for the existence

207 and stability of the interior steady state solutions of the conventional NPZ model (see the

208 Supplement S2).

209

\section{$210 \quad 3.2$ Impact of “micro-scale variability” in Closure Model}

\section{$211 \quad$ 3.2.1 Trophic-transfer in food web}

212 The effect of varying the $Z$-grazing rate is shown in Fig. 1a for the conventional NPZ

213 model, and similar results are shown for the NPZ closure model in Fig. 1b and Fig. 1c for

214 two fixed values of $\beta=2.0$ and 3.0. In case of $\beta=2.0$, the stable steady state solution is only

215 obtained for $0<r<1.6$ (for $r>1.6$ only boundary solutions are possible). Zooplankton

216 biomass is consistently higher, and phytoplankton biomass consistently lower, in the NPZ

217 closure model compared to the corresponding conventional NPZ model. The Z-biomass

218 also increases with the level of micro-scale variability in the model.

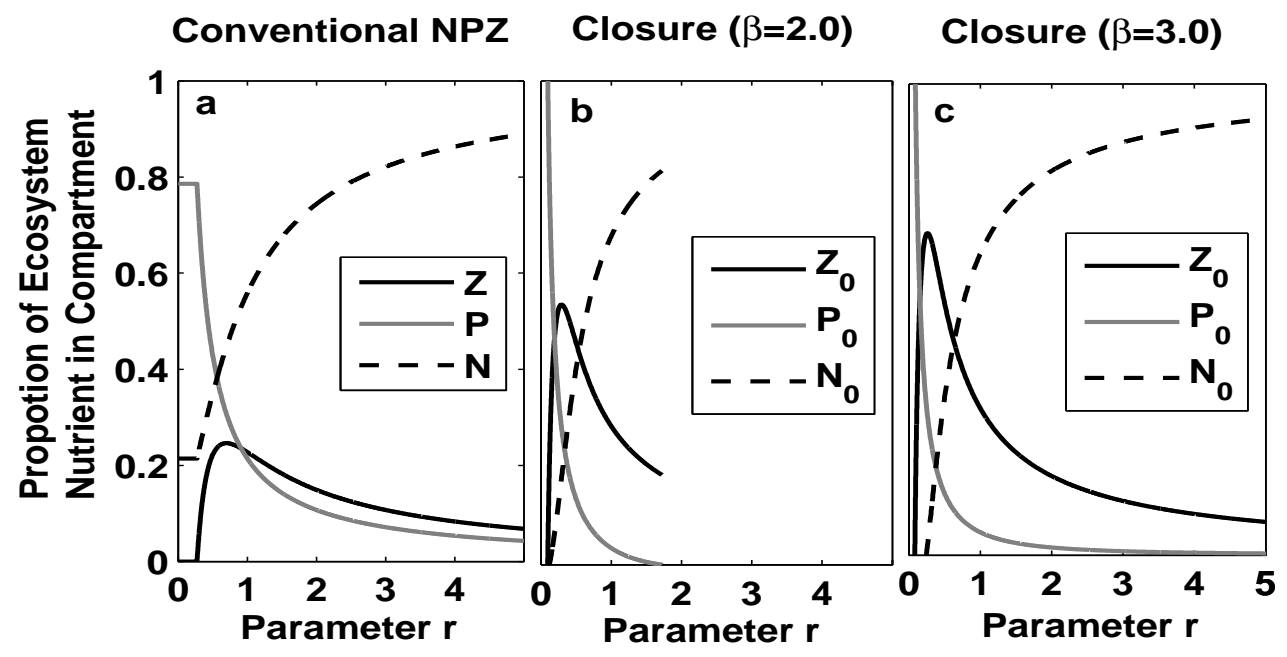


220

221

222

223

224

225

226

227

228

229

230

231

232

233

234

235

236

237

238

239

240

241

242

243

244

245

Fig. 1 Impact of $\beta$ : The proportion of ecosystem nutrient found in compartment is shown on the y-axis in each subfigure (a-c). The effect of varying grazing rate, $r$, based on the parameter set (9) on $N, P$ and $Z$ in a) the conventional NPZ model, and the NPZ closure model b) with $\beta=2.0$ diagram is depicted for the range $0<r<1.6$, and c) with $\beta=3.0$ in the range $0<r<5.0$.

The results are robust, as confirmed by further investigating the three possible cases. We investigate the dynamics and the standing stocks of biomass for the following three cases:

Case (i) $N$-dominating over $P$ and $Z$ biomasses

Case (ii) $P$-dominating over $N$ and $Z$ biomasses

Case (iii) $Z$-dominating over $P$ and $N$ biomasses

To get these three scenarios, we have chosen the following three sets of parameters:

$$
\begin{aligned}
& r=0.8, m=0.2, g=0.1, k=0.5, \gamma=0.3 \quad(N \text {-dominating }) \\
& r=0.5, m=0.3, g=0.15, k=0.5, \gamma=0.3 \quad(P \text {-dominating }) \\
& r=0.5, m=0.2, g=0.1, k=0.5, \gamma=0.3 \quad(Z \text {-dominating })
\end{aligned}
$$

In case of $\mathrm{N}$-dominating (10a), the standing stock of planktonic variables for the conventional NPZ model is $p=0.18, z=0.35, n=0.47$, while for $P$-dominating case (10b), the standing stock is $p=0.43, z=0.22, n=0.35$. In case of $Z$-dominating (10c), the standing stock of planktonic variables for the conventional NPZ model is $p=0.29, z=0.39, n=0.33$.

The standing stocks of planktonic variables for the conventional NPZ model are shown in Fig. 2a-c respectively. For the same three-parameter sets, the time series of planktonic variables for the NPZ closure model at different $\beta$ values are drawn in Fig. 3. In each of these figures, the standing stocks of $N, P$ and $Z$ for the NPZ closure model are compared with the standing stock of the conventional NPZ model.

In all three cases, the standing stock of zooplankton biomass is higher and that of 
246 phytoplankton is lower in the NPZ closure model, than in the corresponding conventional

247 NPZ model. Increasing micro-scale variability, $\beta$, enhances the zooplankton biomass while

248 it reduces the phytoplankton biomass. Furthermore, in the NP closure model (Mandal et al.,

249 2014), $\beta$ enhances the biomass of phytoplankton, which is the highest trophic level in that

250 model. Thus, increasing micro-scale patchiness in the plankton distributions favours the

251 highest trophic level present in either closure model. This suggests that natural ecosystems

252 with high variability may favour trophic transfer upwards within the food chain. These

253 results were obtained without explicitly accounting for the complicated behavioural

254 dynamics of zooplankton (e.g., active swimming and optimal foraging strategies), which are

255 beyond the scope of this study.

256

257

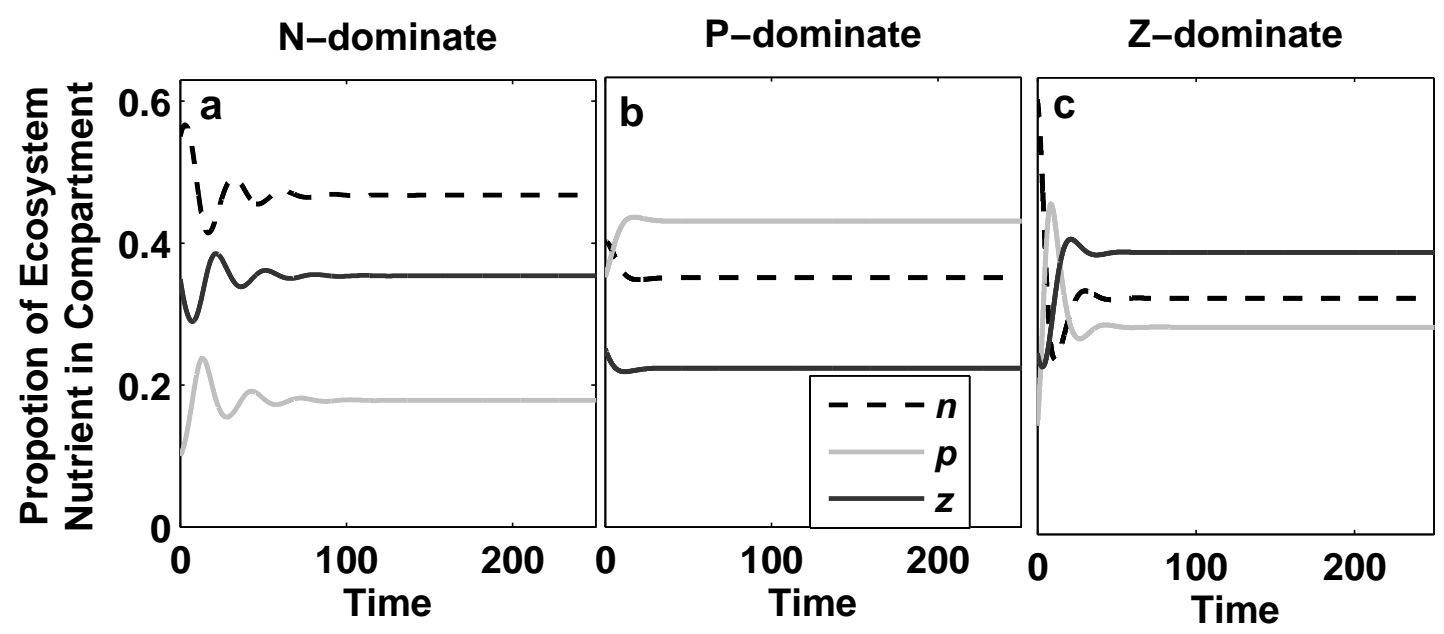

258 Fig. 2 Conventional NPZ model: The y-axis represents the 'proportion of ecosystem

259 nutrient found in compartment' in each subfigure. Time-series of $N, P$ and $Z$ from the

260 conventional NPZ model for three cases: a) $N$-dominance, b) $P$-dominance, and c) $Z$ -

261 dominance, obtained using three different parameter sets (10a-c), respectively. 

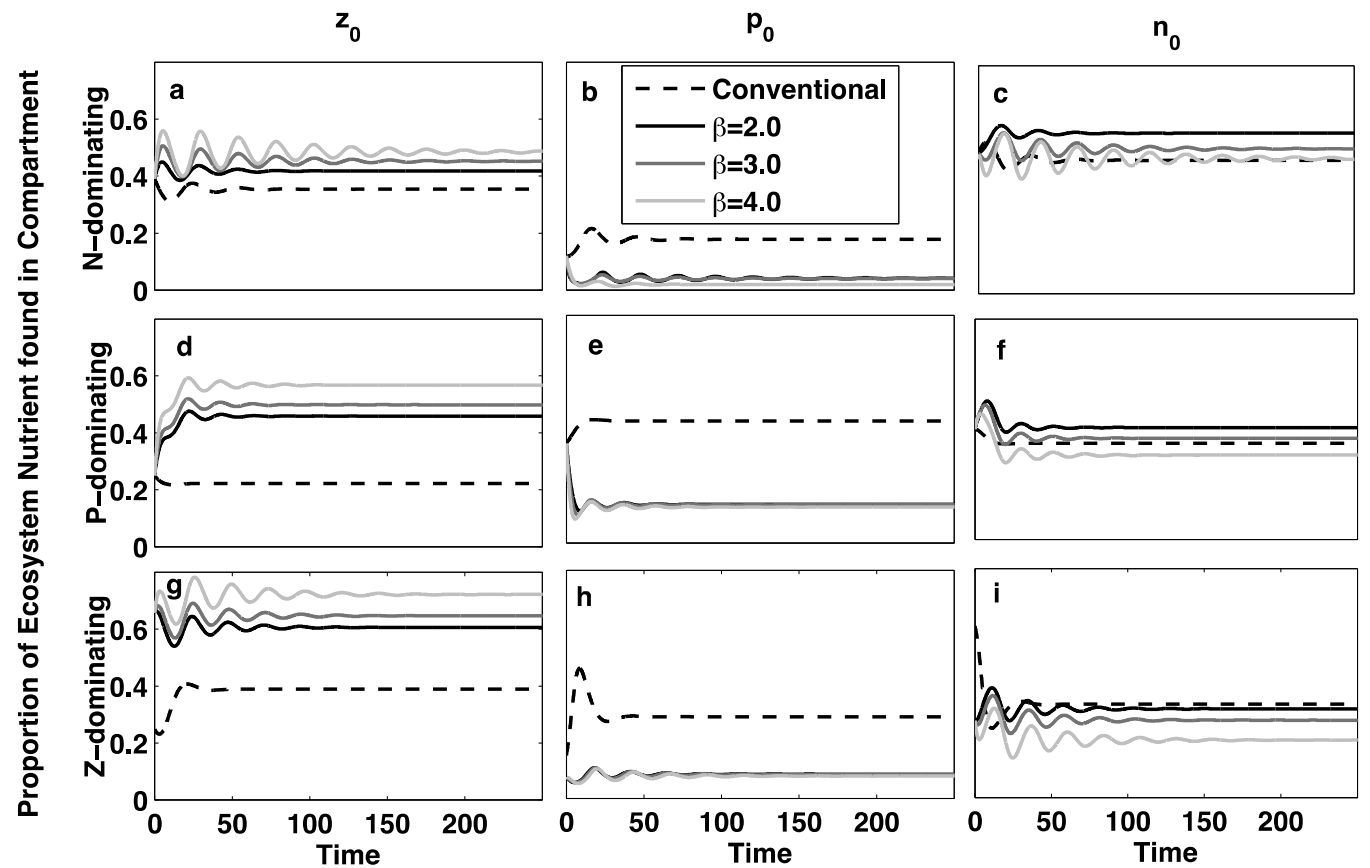

263 Fig. 3 In each three cases, y-axis represents the proportion of ecosystem nutrient found in

264 compartment. At different values of micro-scale variability, $\beta$, the time-series of mean-field

265 concentrations of i) zooplankton, ii) phytoplankton, and iii) nutrient for three possible cases

266 of NPZ closure model: a-c) $\boldsymbol{N}$-dominating case, d-f) $\boldsymbol{P}$-dominating case and $\mathbf{g}$-i) $\boldsymbol{Z}$ dominating case.

\subsubsection{Minimum micro-scale variability threshold for stability in closure model}

A minimum threshold of variability is required for the stability of the NPZ closure

272 model. The shaded region in the two-parameters bifurcation diagram (Fig. 4) is the

273 parameter domain for stability. For each value of parameter $r$, there is a minimum threshold

274 of micro-scale variability $\beta$ required for interior solutions. The same was found for the NP

275 model (Mandal et al., 2014) in which so-called $\beta^{*}$ is the minimum threshold variability

276 beyond which interior solutions exist in the closure model. Below $\beta^{*}$ only boundary

277 solutions are possible, which are not relevant for analysis as we are mainly interested in

278 interior solutions for which all variables are non-zero. 


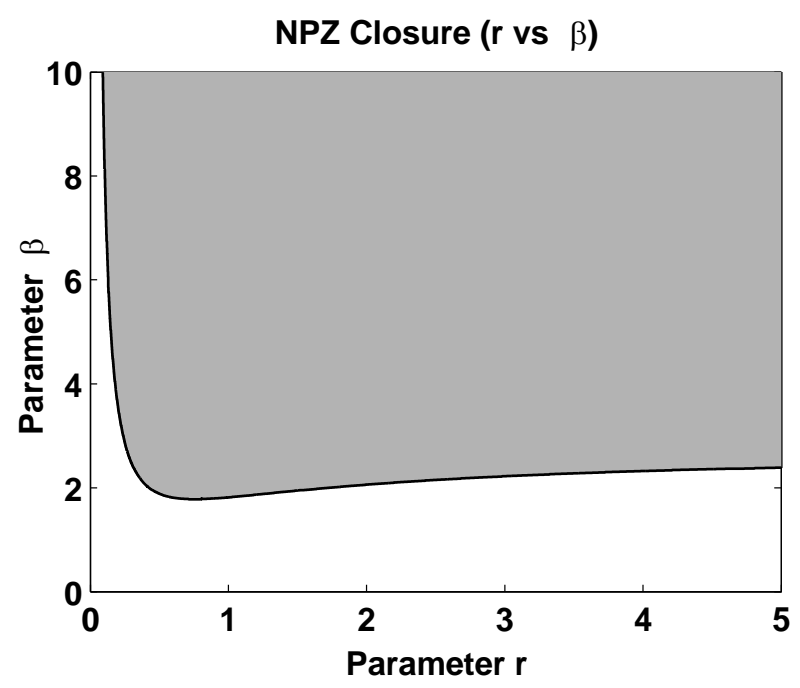

280 Fig. 4 NPZ closure model $(\boldsymbol{r}, \boldsymbol{\beta})$ : Two-parameter $(r, \beta)$ bifurcation diagram for parameter 281 set (9). The shaded region in the diagram is the parameter domain for which the NPZ 282 closure model has stable steady state solutions and in which all variables coexist. There is a 283 minimum $\beta$, below which no stable steady state solutions exist. The values of other 284 parameters are used from parameter set (9).

\subsubsection{Variability favours higher probability of coexistence and greater biodiversity}

Variability in nature is ubiquitous and plays a vital role in determining ecological

288 patterns and hence traits. The heterogeneity of habitats and landscapes is undoubtedly a key

289 to biodiversity. Many authors have reported that heterogeneity leads to increased species

290 richness. In fact, the overall mean effect of heterogeneity on species richness is positive

291 across taxa and regions. Most have claimed that heterogeneity is in all cases beneficial to

292 biodiversity (Doi et al., 2013; Katayama et al., 2014; Calbet et al., 2015). Biodiversity

293 certainly depends upon the ecological pattern considered (landscape heterogeneity,

294 spatially- or temporally-variable environments, species size range, traits heterogeneity etc).

295 Similar to our finding that variability enhances the biomass of the highest trophic level

296 present, we also find that the potential for species richness increases with variability. This is

297 because the stability domain $(r, k)$ in Fig. 5 widens with increasing level of variability in the 
298 closure model. This parameter domain defines the region over which coexistence of species 299 is possible. A wider stability domain $(r, k)$ is found for the closure model than for the 300 corresponding conventional model, although some limited regions of parameter space that 301 are stable for the conventional model may become unstable for the closure model at low 302 values of $\beta$ (Supplemental Figure S2). The same ecological pattern (a wider stability domain 303 at higher variability) is found with all other parameter combinations, and this finding holds 304 for both the NP and NPZ closure models. The result suggests that natural systems with 305 greater micro-scale variability may have the potential to sustain greater biodiversity, i.e. that 306 many different species with a wide range of parameter values may be able to coexist. 307 Although a wider stability domain does not guarantee greater biodiversity, a narrower 308 stability domain (as found at lower variability) necessarily reduces the set of viable 309 combinations of parameter values (corresponding to trait values), and therefore limits 310 potential biodiversity.

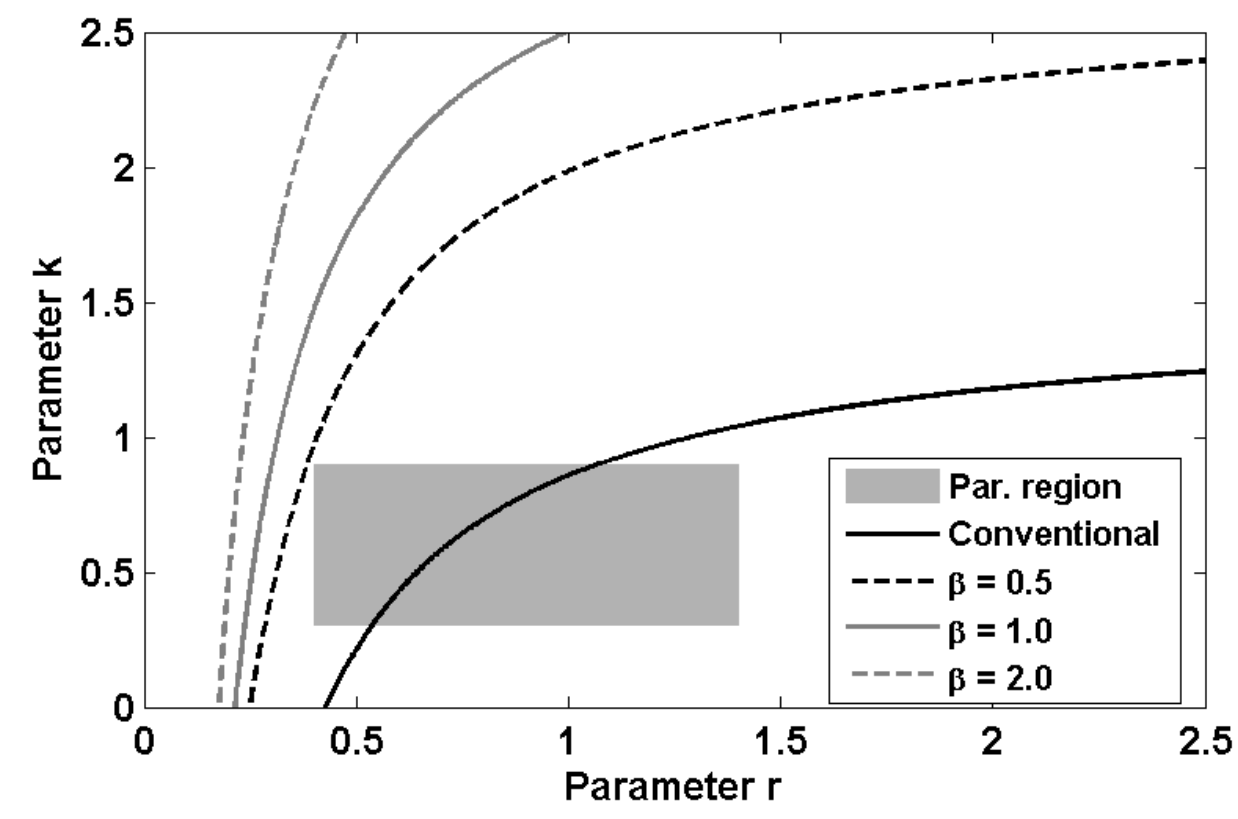


Fig. 5. Two-parameter $(r, k)$ bifurcation diagram for the conventional NPZ and NPZ

314 closure models for different values of $\beta$. The region underneath each curve represents the

315 stable parameter space for each value of $\beta$, respectively. For all curves shown, values of

316 other parameters were: $m=0.4, g=0.3, \gamma=0.3$. The shaded area shows the realistic

317 parameter domain, based on reported values, for $r$ and $k$ (Table 1).

319 3.2.4 Coefficient of variation $\left(C V_{P}\right)$ of phytoplankton in NPZ closure model

320 Dobell et. al. $(2009,2014)$ reported intermittency in micro-scale phytoplankton data

321 which they observed in Tokyo Bay with microstructure profiler TurboMAP-L. This

322 instrument carries a laser fluorescence probe that resolves $\mathrm{mm}$ scale spatial variability of

323 phytoplankton distribution, yielding high standard deviation of fluorescence signals. The

324 "coefficient of variation $(C V)$ " is defined as a ratio of standard deviation to the mean of a

325 variable. Since $C V_{P}$ is a measurable quantity, it is important to investigate how $C V_{P}$ and

326 micro-scale variability impact the dynamics of plankton ecosystems.

327 The relationship between $C V_{P}$ and variability, $\beta$, in the NPZ closure model is shown

328 in Fig. 6 using the parameter set (9), with different curves drawn by varying the parameter $m$,

329 which is directly related to $v_{\max }$ as $m=M / v_{\max }$. Since the phytoplankton growth rate $v_{\max }$

330 depends on light intensity, it varies with vertical depth in seawater. As the intensity of light

331 decreases with the depth from the sea surface, it is assumed that the maximum growth rate

332 of phytoplankton $v_{\max }$ decreases which affects the coefficient of variation of the

333 phytoplankton $C V_{P}$ in the seawater. The $C V_{P}$ is found to be greater than 1 for all stable

334 steady states solutions in the NPZ closure model. Further, $C V_{P}$ and $\beta$ are positively

335 correlated in the NPZ closure model. 


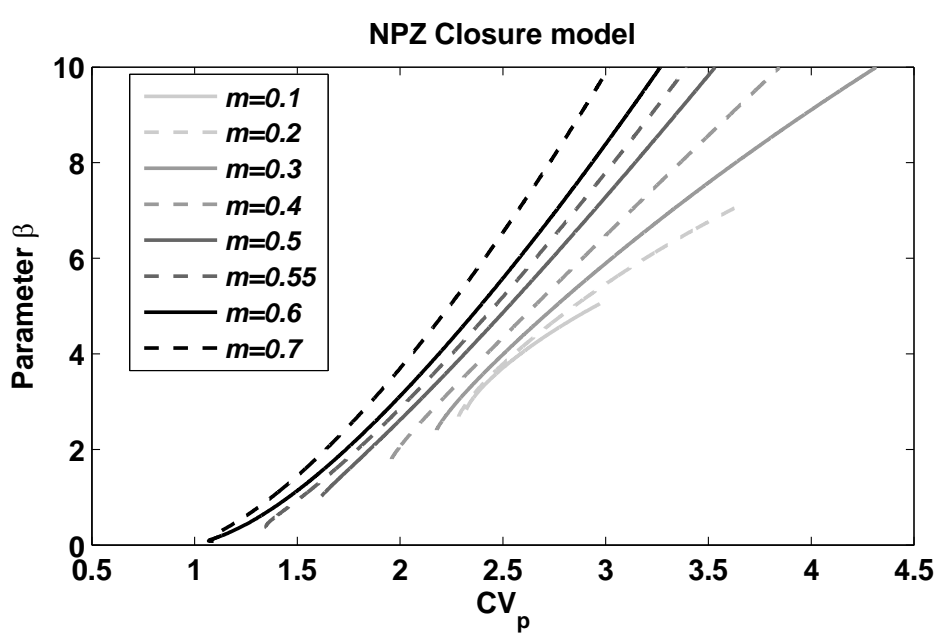

337 Fig. 6 NPZ Closure model $\left(\boldsymbol{C} \boldsymbol{V}_{\boldsymbol{P}}\right.$ and $\left.\boldsymbol{\beta}\right)$ : Coefficient of variation of phytoplankton $\left(C V_{P}\right)$ is

338 shown with respect to micro-scale variability, $\beta$, for different values of $m$.

341 similar way, and $C V_{P}$ is greater than one for all stable solutions (Fig. 7). However, $C V_{P}$ is

342 less than one for some $\beta$ values, at which boundary solutions exist. $C V_{P}$ and $\beta$ are positively

343 correlated for both the NPZ and NP closure models.

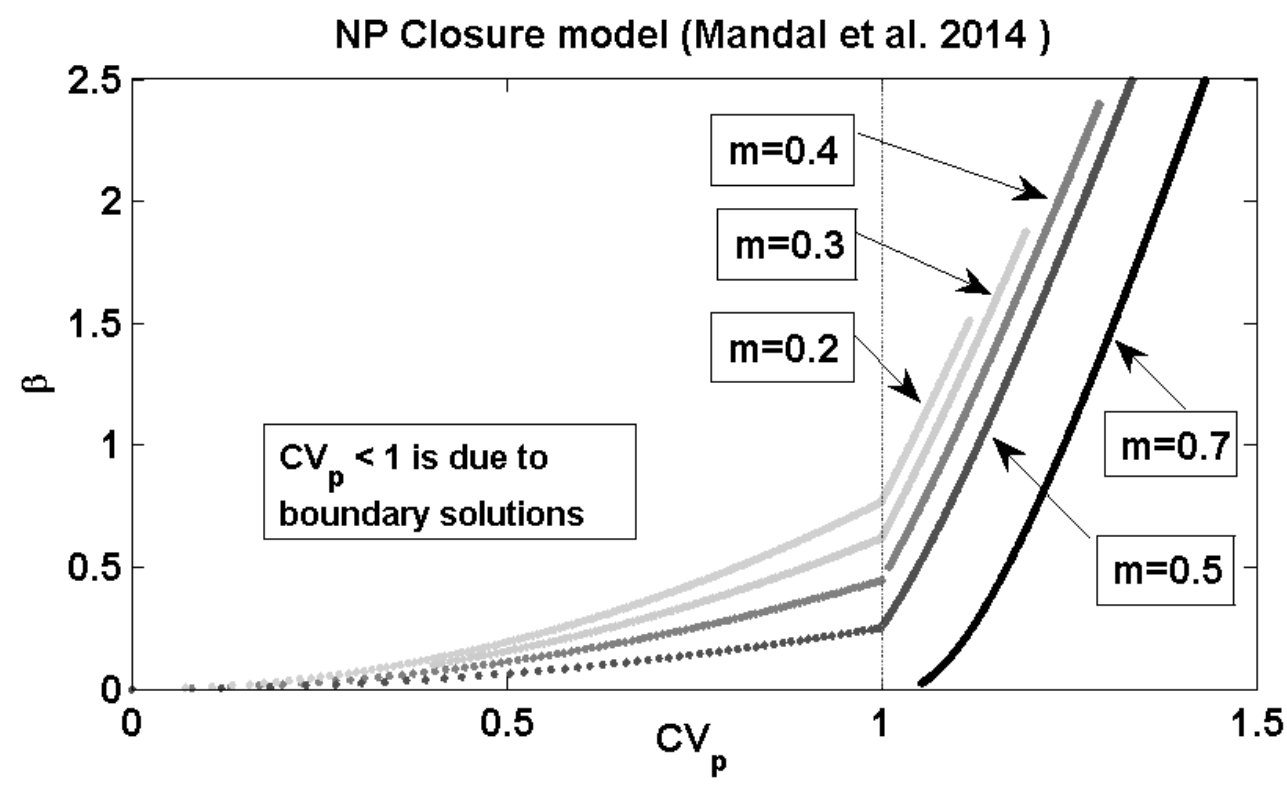

345 Fig. 7 NP Closure model case: Total micro-scale variability, $\beta$, versus coefficient of 
346 variation $\left(C V_{P}\right)$ for phytoplankton in the absence of $Z$ (Mandal et al., 2014). In this case, for

347 boundary solutions in the NP closure model, $C V_{P}$ may be $<1$, while for all stable solutions $348 \quad C V_{P}>1$.

Mandal et al., (2014) presented observed profiles of chlorophyll (phytoplankton)

351 collected at the mouth of Tokyo Bay, Japan at different observation stations in May 2011, 352 and at one particular station from 2006 to Feb 2008, up to 120-m depth from the ocean 353 surface. The observed coefficient of variation for phytoplankton was less than one in the 354 interior of Tokyo Bay (coastal area), and greater than one far away from the coastal area. 355 Theoretical models (NP and NPZ) predict that $C V_{P}$ is always greater than 1 for stable steady 356 state solutions. The theoretical results regarding $C V_{P}>1$ are consistent with the 357 observations (Mandal et al., 2014) in open water where $C V_{P}>1$. In the coastal region 358 (interior of Tokyo bay), a very low scale of heterogeneity may prevent the TubrboMAP-L 359 profiler from detecting high variance against high background phytoplankton mean, which 360 could result in observed values of $C V_{P}<1$. In open water, the variability is very high 361 relative to the mean-field phytoplankton biomass. In this case, the phytoplankton aggregates 362 are abundant and a wide range of parameter space allows stable solutions. This suggests that 363 natural systems with greater micro-scale variability may have the potential to support 364 greater biodiversity of plankton.

\section{4. Conclusions}

367 We have extended the previously presented closure approach to develop an NPZ 368 closure model and applied it to conduct the first modelling study of how micro-scale 369 variability impacts plankton ecosystem dynamics, focusing specifically on the potential for 370 coexistence of species, trophic transfer between multiple trophic levels, and the persistence 
371 of higher trophic levels. Our model predicts a range of values for the coefficient of variation

$372\left(C V_{p}\right)$ of phytoplankton, in agreement with the range observed for Tokyo Bay (Mandal et al.

373 2014). We also aimed to clarify the role of micro-scale variability, $\beta$, in determining the

374 coefficient of variation $\left(C V_{p}\right)$ of phytoplankton. This study has yielded the following

375 answers to the questions posed in the Introduction:

376 a) micro-scale variability enhances the domain of ecosystem stability.

377 b) micro-scale variability enhances trophic transfer from phytoplankton to zooplankton.

378 c) the coefficient of variation $\left(C V_{p}\right)$ of phytoplankton increases with micro-scale variability, $\beta$.

379 Thus we have successfully applied a spatial moment closure approach to predator-prey

380 dynamics, in essence like the terrestrial studies reviewed by Barraquand and Murrel (2013),

381 but here specifically for plankton ecosystems. Spatial heterogeneity increases the diversity

382 of resources and hence the available niche space (structural complexity), which ultimately

383 promotes species coexistence (Hutchinson, 1959) and enhances species persistence through

384 increased probability of finding shelter and refuge from adverse environmental conditions

385 (Svenning and Skov, 2007). Spatial heterogeneity is known to result in the diversification of

386 species via evolutionary adaptation to diverse environmental conditions (Hughes and

387 Eastwood, 2006). Similarly, we find that micro-scale variability increases the domain of 388 trait space over which stable solutions are possible with our closure modelling approach,

389 which suggests that the potential variety of coexisting phytoplankton and zooplankton

390 species increases with micro-scale spatial heterogeneity.

391 The fast growth and continual transport of plankton in water make it essential to account

392 explicitly for the dynamics of the spatial moments (variances and co-variances), which some

393 recent terrestrial moment closure studies have not made explicit functions of the ecological

394 dynamics nor of transport (Barraquand and Murrel, 2013). Still, understanding remains 
quite limited concerning the effects of realistic levels of micro-scale variability, particularly

396 in combination with physical transport, on plankton ecosystems (Mandal et al., 2016).

397 Further advances will require the testing of theoretical predictions against observations. To

398 this end, we have identified three specific testable predictions based on our results herein:

399 1) Micro-scale variability enhances trophic transfer up the food chain,

400 2) Stability of plankton ecosystems requires a coefficient of variation for

3) Total micro-scale variability, $\beta$, can be predicted based on observed $C V_{P}$.

404 Nevertheless, given that high levels of micro-scale variability are observed ubiquitously 405 in the ocean, our findings herein reinforce the conclusions of previous studies (Mandal et 406 al., 2014; Doubell et al., 2009, 2014), namely that the large-scale impact of micro-scale 407 distributions may not be ignored. Furthermore, the relationship identified herein between the 408 coefficient of variation $\left(C V_{P}\right)$ of phytoplankton and the standardized total variability, $\beta$, may 409 help to estimate the latter from observed $C V_{P}$. Thus, $C V_{P}$ may be useful as an index for the 410 potential of aquatic systems to support plankton biodiversity. 


\section{Acknowledgements}

420 We thank Mr. Sean Tippett for careful reading of the manuscript. This study was

421 supported financially by two CREST Projects (PIs SLS and HY) funded by the Japan 422 Science and Technology Agency.

423 
1. Azam F and Worden AZ (2004) Microbes, molecules and marine ecosystems. Science 303:1622-1624. (DOI: 10.1126/science.1093892)

2. Allen JC (1975) Mathematical models of species interactions in space and time. Am. Nat. 109:319-342.

3. Barraquand F and Murrel DJ (2013) Scaling up predator-prey dynamics using spatial moments equations. Methods in Ecology and Evolution 4:276-289

5. Brentnall SJ, Richards KJ, Brindley J, Murphy E (2003) Plankton patchiness and its effect on larger-scale productivity. J. Plankton Res. 25:121-140.

4. Bertilsson S, Hansson LA, Graneli W and Philibert A (2003) Size-selective predation on pelagic microorganisms in Arctic freshwaters. J. Plankton Res. 25: $621-631$.

6. Briggs C and Hopes M (2004) Stabilizing effects in spatial parasitoid-host and predator-prey models: a reviewer. Theo Pop Bio 65: 299-315.

7. Bolker BM and Pacala SW (1997) Using moment equations to understand stochastically driven spatial pattern formation in ecological systems. Theor. Popul. Biol. 52:179-197.

8. Calbet A, Agersted MD et al., (2015) Heterogeneous distribution of plankton within the mixed layer and its implications for bloom formation in tropical seas. Scientific Reports, 5:11240, Doi: 10.1038/srep11240

9. Carpenter SR and Kitchell JF (1984) Plankton community structure and limnetic primary production. American Naturalist 124:159-172.

10. Carpenter SR and Kitchell JF (1988) Consumer control of lake productivity. Bio 448 Science 38: 764-769. 
11. Clark DR and Flynn KJ (2000) The relationship between the dissolved inorganic carbon concentration and growth rate in marine phytoplankton. Proc $R$ Soc $B$ 267:953-959. (DOI: 10.1098/rspb.2000.1096)

12. Crowley PH (1981) Dispersal and the stability of predator-prey interactions. Am. Nat. 118:673-701.

13. Cyr H 1(998) Grazing of cladoceran- and copepod-dominated zooplankton communities in oligotrophic lakes. Canadian Journal of Fisheries and Aquatic Sciences 55: 414-422

14. Doi H et al., (2013) Isotopic evidence for the spatial heterogeneity of the planktonic food webs in the transition zone between river and lake ecosystems, PeerJ Doi: 10.7717/peerj.222

15. Doubell MJ, Yamazaki H, Kokubu Y (2009) An advanced laser-based fluorescence microstructure profiler (TurboMAP-L) for measuring bio-physical coupling in aquatic systems. $J$ Plankton Res 31(12):1441-1452. (DOI: 10.1093/plankt/fbp092)

16. Doubell MJ, Prairie JC, Yamazaki H (2014) Millimeter scale profiles of chlorophyll fluorescence: Deciphering the microscale spatial structure of phytoplankton. Deep-Sea Res II,101: 207-215. (DOI: 10.1016/j.dsr2.2012.12.009)

17. Edward AM and Brindley J (1996) Oscillatory behaviour in a three-component plankton population model. Dyn. Stabil. Syst. 11:347-370

18. Eppely RW, Rogers JN, McCarthy JJ (1969) Half-saturation constants for the uptake of nitrate and ammonia by marine phytoplankton. Limnol Oceanogr $14: 912-920$ 
19. Fasham MJR (1993) Modelling the marine biota. In: The global carbon cycle. (ed. Heimann M), Berlin: Springer-Verlag. pp. 457-504.

20. Ferguson NM, Donnelly CA, Anderson RM (2001) The foot and mouth epidemic in Great Britain: pattern of spread and impact of interventions. Science 292:1155-1160.

21. Filipe JAN and Gibson GJ (2001) Comparing approximations to spatio-temporal models for epidemics and local spread. Bull. Math. Biol. 63:603-624.

22. Filipe JAN and Maule MM (2003) Analytical methods for predicting the behavior of population models with general spatial interactions. Math. Biosci. $183: 15-35$

23. Foloni-Neto H, Tanaka M, Joshima H and Yamazaki H (2015) A comparison between quasi-horizontal and vertical observations of phytoplankton microstructure. J. plankton Res., doi:10.1093/plankt/fbv075.

24. Franks PJS, Wroblewski JS, Flierl GR (1986) Behavior of a simple plankton model with food-level acclimation by herbivores. Marine Biol 91:121-129. (DOI: 10.1007/BF00397577)

25. Franks PJS (2002) NPZ models of plankton dynamics: their construction, coupling to physics, and application. $J$ Oceanogr 58:379-387. (DOI: 10.1023/A:1015874028196)

26. Holt RD, Hassell MP (1993) Environmental heterogeneity and the stability of host-parasitoid interactions. J. Anim. Ecol. 62:89-100.

27. Hughes C, Eastwood R (2006) Island radiation on a continental scale: exceptional rates of plant diversification after uplift of the Andes. Proceedings of the National Academy of Sciences 103:10334-10339.Huisman J, Thi NNP, Karl DM, Sommeijer B 
(2006) Reduced mixing generates oscillations and chaos in the oceanic deep chlorophyll maximum. Nature 439:322-325. (DOI: 10.1038/nature04245)

28. Hutchinson GE (1959) Homage to Santa Rosalia or why are there so many kinds of animals? The American Naturalist 93:145-159

29. Jansen VAA (1995) Regulation of predator-prey systems through spatial interactions: a possible solution to the paradox of enrichment. Oikos. 74:384-390.

30. Katayama N, et al. (2014) Landscape heterogeneity-biodiversity relationship: effect of range size, PLOS ONE 9:03359

31. Lehman JT, Botkin DB, Likens GF (1975) The assumptions and rationales of a computer model of phytoplankton production dynamics. Limnol Oceanogr $20: 343-364$.

32. Lewis MA and Pacala S (2000) Modeling and analysis of stochastic invasion processes. J. Math. Biol. 41:387-429.

33. Loreau M (2001) Microbial diversity, producer-decomposer interactions and ecosystem processes: a theoretical model. Proc $R$ Soc B 268:303-309. (DOI: 10.1098/rspb.2000.1366)

34. MacIsaac JJ and Dugdale RC (1969) The kinetics of nitrate and ammonia uptake by natural populations of marine phytoplankton. Deep-Sea Res 16:45-57. (DOI: 10.1016/0011-7471(69) 90049-7)

35. Mandal S, Locke C, Tanaka M and Yamazaki H (2014) Observations and models of highly intermittent Phytoplankton distributions. PLOS ONE. 9(5): e94797. (Doi: 10.1371/journal.pone.0094797)

36. Mandal S, Homma H, Priyadarshi A, Burchard H, Smith SL, Wirtz KW and Yamazaki H (2016). A 1D physical-biological model of the impact of highly 
intermittent phytoplankton distributions, $J$ Plankton Res 0(0): 1-13 (DOI: 10.1093/plankt/jbw019)

37. McCann K, Hastings A, Harrison S, Wilson W (2000) Population outbreaks in a discrete world. Theor. Popul. Biol. 57:97-108.

38. Murdoch WW, Oaten A (1975) Predation and population stability. Adv. Ecol. Res. 9:1-131.

39. Murdoch WW, Briggs CJ, Nisbet RM, Gurney WSC, Stewart-Oaten A (1992)

40. Murrell DJ, Dieckmann U, Law R (2004) On moment closures for population dynamics in continuous space. J. Theor. Biol. 229:421-432.

41. Neubert MG, Klepac P, van den Driessche P (2002) Stabilizing dispersal delays in predator-prey metapopulation models. Theor. Popul. Biol. 61:339-347.

42. Okubo A and Levin S (1980) Diffusion and ecological problems: modern perspectives, second ed. In: Interdisciplinary Applied Mathematics. 17:466 Springer, New York.

43. Peter RH and Downing JA (1984) Empirical analysis of zooplankton filtering and feeding rates. Limnology and Oceanography 29: 763-784.

44. Poulin FJ and Franks PJS (2010) Size-structured planktonic ecosystems: constraints, controls and assembly instructions. J Plankton Res 32(8):1121-1130. (DOI: 10.1093/plankt/fbp145)

45. Reeve JD (1988) Environmental variability, migration and persistence in hostparasitoid systems. Am. Nat. 132:810-836.

46. Rohani P, May RM, Hassell MP (1996) Metapopulations and equilibrium stability: the effects of spatial structure. J. Theor. Biol. 181:97-109. 
47. Sprules WG (1980), Zoogeographic patterns in the size structure of zooplankton communities, with possible applications to lake ecosystem modelling and management. In Kerfoot, W. C. (ed.), Evolution and ecology of zooplankton

communities, University Press of England, Hanover (1980), pp. 642-656

48. Steel JH and Henderson EW (1981) A simple plankton model. Am Nat 117:676691. (DOI: 10.1086/283752)

49. Steel Henderson EW (1992) The role of predation in plankton models. J. Plankton Res. 14(1):157-172 (DOI: 10.1093/plankt/14.1.157)

50. Sterner RW (1989) The role of grazers in phytoplankton succession. In Sommer, U. (ed.), Plankton Ecology: Succession in Plankton Communities. Springer, New York: $107-169$.

51. Storm SL and Welschmeyer NA (1991) Pigment-specific rates of phytoplankton growth and microzooplankton grazing in the open subarctic Pacific Ocean. Limnol. Oceanogr. 36:50-63.

52. Svenning JC, Skov F (2007) Ice age legacies in the geographical distribution of tree species richness in Europe. Global Ecology and Biogeography 16:234-245.

53. Wallhead PJ, Martin AP and Srokosz MA (2008) Spatially implicit plankton population models: Transient spatial variability. $J$ Theo Bio 253:405-423. (DOI: 10.1016/j.jtbi.2008.03.020)

54. Weisser WW, Jansen VAA, Hassell MP (1997) The effects of a pool of dispersers on host-parasitoid systems. J. Theor. Biol. 189:413-425.

55. Yool A (1998) The dynamics of open-ocean plankton ecosystem models. PhD Thesis. University of Warwick 